\title{
ECONOMIC ANALYSIS OF THE LIFE-CYCLE COST STRUCTURE FOR RAILWAY TRAFFIC CONTROL SYSTEMS
}

\author{
Tomasz Ciszewski ${ }^{1, a,{ }^{*}}$ and Waldemar Nowakowski ${ }^{2, b}$ \\ ${ }^{1}$ Kazimierz Pulaski University of Technology and Humanities in Radom, Faculty of Transport and \\ Electrical Engineering, Malczewskiego 29, 26-600 Radom, Poland \\ ${ }^{2}$ Kazimierz Pulaski University of Technology and Humanities in Radom, Faculty of Transport and \\ Electrical Engineering, Malczewskiego 29, 26-600 Radom, Poland \\ at.ciszewski@uthrad.pl, ${ }^{b}$ w.nowakowski@uthrad.pl \\ *Corresponding author
}

Cite as: Ciszewski, T., Nowakowski, W. (2018). Economic analysis of the life-cycle cost structure for railway traffic control systems, Ekonomicko-manazerske spektrum, 12(1), 30-43.

Available at: dx.doi.org/10.26552/ems.2018.1.30-43

\begin{abstract}
In the case of complex technical systems that should deliver long life, high availability, safety and reliability, such as railway traffic control systems, the ownership costs many times exceed the costs of its acquisition. Therefore, infrastructure operators in order to make optimal economic decisions, regarding the systems purchase or and modernization, expect that system delivers will give complex information not only about the initial costs of purchasing the system, but also about the costs of its operation and liquidation. It allows to include in budget plans, growing requirements for the reliability availability of infrastructure as well as crucial issue - the traffic safety. Considering the widespread use of railway traffic control systems, which are part of the railway infrastructure, even small savings obtained for individual systems can be resulted into significant financial benefits for infrastructure owners and operators. One of the methods which helps to consider all of the above-mentioned types of costs is the Life Cycle Cost (LCC) analysis. In the case of railway traffic control systems it is a mandatory part of RAMS (Reliability, Availability, Maintainability, Safety) / LCC analysis. Its requirements are defined in the European Union directives, and the methodology is included in the CENELEC standards. The methodology of the LCC analysis, including economic aspects as well as safety and reliability requirements specific to railway traffic control systems was presented by the authors. LCC structure for three various examples of railway traffic control systems were considered. This economic analysis includes level crossing protection system, axle counting system and automatic block signalling. Based on these examples the differences in the LCC structure for individual systems were presented.
\end{abstract}

Keywords: Life-Cycle Cost, LCC, railway traffic control systems, RAMS

JEL Classification: L92, R41, R42

\section{Introduction}

\subsection{Review}

Recently, in the international railway transport is a great pressure, mainly from the railway operators, to upgrade railway infrastructure. The changes are also stimulated by the increasing quality and technical requirements for railway products and changes in standards and legal 
regulations. Due to the high costs associated with infrastructure modernization projects, they should be carefully analysed for their feasibility and cost effectiveness, which will not only allow to correctly select the scope of modernization but also to quantify its measurable economic effects. Normally, feasibility and cost-effectiveness analyses are carried out in several variants, which allow to compare the effectiveness of particular solutions in relation with the state of the existing, i.e. pre-modernization state. It should be remembered that a comprehensive efficiency analysis must take into account all phases of the life cycle of a modernized object.

At the same time, in relation to the rail infrastructure and rail transport, in the analysis the question of ensuring a high level of safety cannot be omitted, stated by Nowakowski et al. (2016). In the railway industry the regulations in this regard are multifaceted. The European Union Directives are the basic documents containing the relevant recommendations, including Directive 2008/110/EC of 16 December 2008 on safety on the Community's railways (Railway Safety Directive) and Directive 2008/57/EC of 17 June 2008 on the interoperability of the rail system within the Community, which is a consolidated version of the existing interoperability directives for high speed rail (96/48/EC) and conventional rail (2001/16/EC). In the train industry CENELEC (European Committee for Electrotechnical Standardization): standards are a next group of prescriptive documents concerning quality and the safety requirements (EN50126, EN-50128, EN-50129 and EN-50159).

The International Railway Industry Standard (IRIS), developed under the auspices of UNIFE (European Railway Industry Association) and with the participation of major rail industry manufacturers (inter alia Bombardier Transportation, Alstom Transport, Siemens Transportation) has increasingly more importance, argued by Calixto (2013). The quality requirements for railroad manufactured products included in the IRIS standard, concern among others, RAMS analysis (Reliability, Availability, Maintainability, Safety), and LCC (Life Cycle Cost) - analysis of the total life cycle cost of the product.

The standardized approach allows to combine both important aspects of the issue, i.e. the economic impact of the project and the availability, safety and reliability of the infrastructure throughout its life cycle. At the same time, it provides expressed in costs, comprehensive and clear information on the various consequences of the adopted modernization concepts, according to Puz \& Bogensperger (2013).

\subsection{Principles of operation of the analysed railway traffic control systems}

\subsubsection{Level crossing protection system}

Level crossing protection systems are used to alert users of roads about approaching trains, and thus are an important component of the railway infrastructure affecting the railway safety as well as the traffic safety, according to Bester \& Torun (2014), and Burdzik et al. (2016). Warning is accomplished by means of road signals and acoustic signal generators (buzzer or bell). In addition, the level crossing can be equipped with barriers (B) and warning shields (Level crossing warning, LCW). Warnings are triggered when the train is approaching to the level crossing, as a result of the train impact at activation points. Wheel sensors (WS) and induction loops are usually used as the activation points. Detection of the approaching train is transmitted to the central control unit, which initiates the warning. Then the road signals (S) and acoustic signals are activated, and provide the appropriate signal on the level crossing warning shield for the selected direction. The next step is the barriers lowering. 
Figure 1: LCPS equipment and its impact zone on the level crossing (double-track railway line)

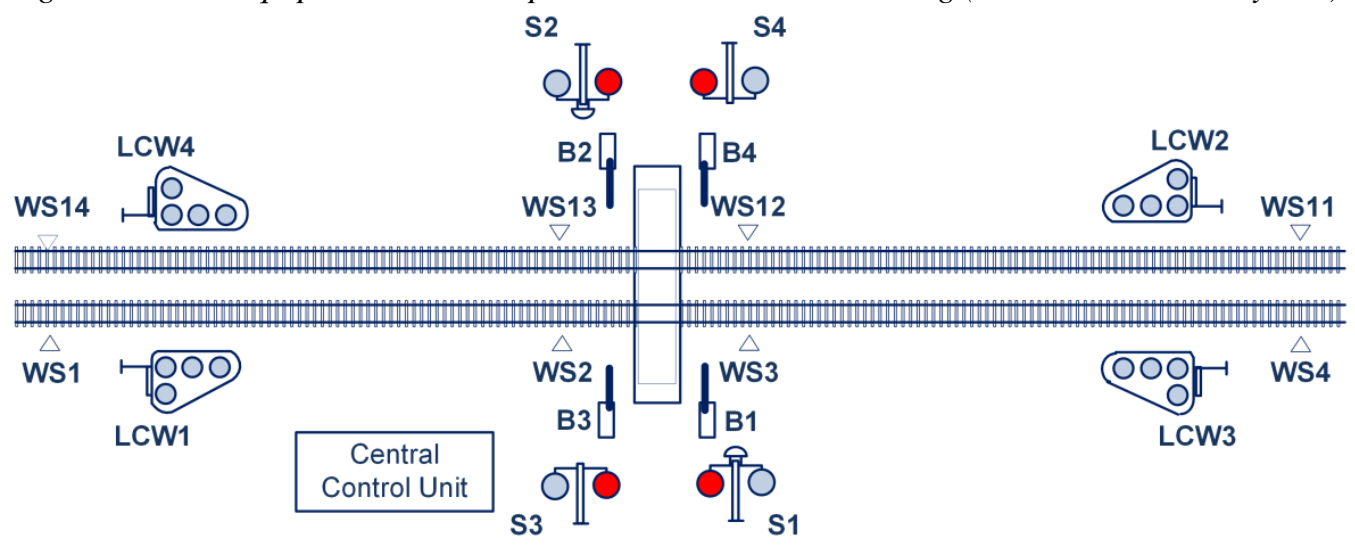

Source: own study

The entrance of the train in the area controlled by the deactivation points causes the switching off an acoustic signal. If the passing zone is left by the train the warning shield are disabled and the barriers starts opening. After opening the barriers road signals are deactivated. The manual control panel allows the manual closing and opening of the level crossing in special cases, argued by Mikulski \& Młynczak (2011), and Nowakowski et al. (2017).

In modern LCPS the remote maintenance system and automatic collection of information about operation of level crossings are often used. These features are available by the application of the PLCs (Programmable Logic Controller) in LCPS. Concept of modern LCPS based on the reliability structure " 2 of 2 " and the peripheral groups for train detection, roadside signals and barriers. System faults are detected by comparing the information between the two independent channels, based on Lewinski \& Perzynski (2010).

\subsubsection{Axle counting systems}

As the train traffic needs to be run so that a safe distance between vehicles is kept, it is necessary to receive information about the trains' location. This task is accomplished by railway track occupancy control systems. There are many methods of this control, the most modern ones are axle counting systems (ACS), which use wheel sensors (Figure 2). A single track section of the track system has two possible initial states: clear or occupied.

Source: own study

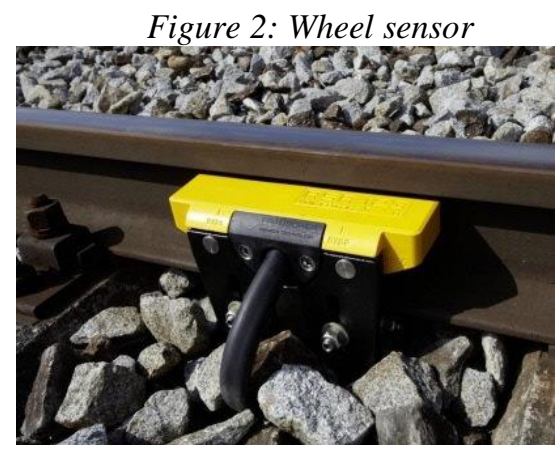

The occupied state takes place when a positive number of axles is detected between two detection points placed at the beginning and at the end of the section, the clear state takes place when the total number of axles detected is equal to zero. A fault state is when one of the detectors is damaged or when the system shows the occupied state, whereas in fact it is clear (there are no vehicles in the section). In this case, the operator is obliged to run a reset procedure, as a result of which the system will wait for a test drive of a vehicle. The necessity to reset track 
sections results in the fact that the system operator should have the access to the diagnostic information. The system in the reset state goes to the clear state only after balancing the number of axles in the section, as a result of a rolling stock crossing the section. The reset function should not be available for the sections which are permanently damaged. That is why, on the basis of the balance of the axles, the states of individual sections, i.e. occupied, clear, section after reset, fault, are being defined by the ACS, stated by Kornaszewski et al. (2017).

\subsubsection{Block signalling}

An automatic block signalling is used for automatic train traffic regulation on the railway track with a safe distance between them. The railway track equipped with the automatic block signalling is divided into block sections. The length of the section depends on the braking distance of the fastest train that can move on this railway track, according to Kornaszewski et al. (2017), as shown in Figure 3. Each section is equipped with its intermediate signal The station exit signal serves the role of the first block signal, whereas the home station's signal serves the role of the last signal. In the case of bi-directional traffic, signals are placed on both sides of the railway track. The automatic block signalling consists of:

- track occupation detection system,

- signalling components and devices,

- interlocking system.

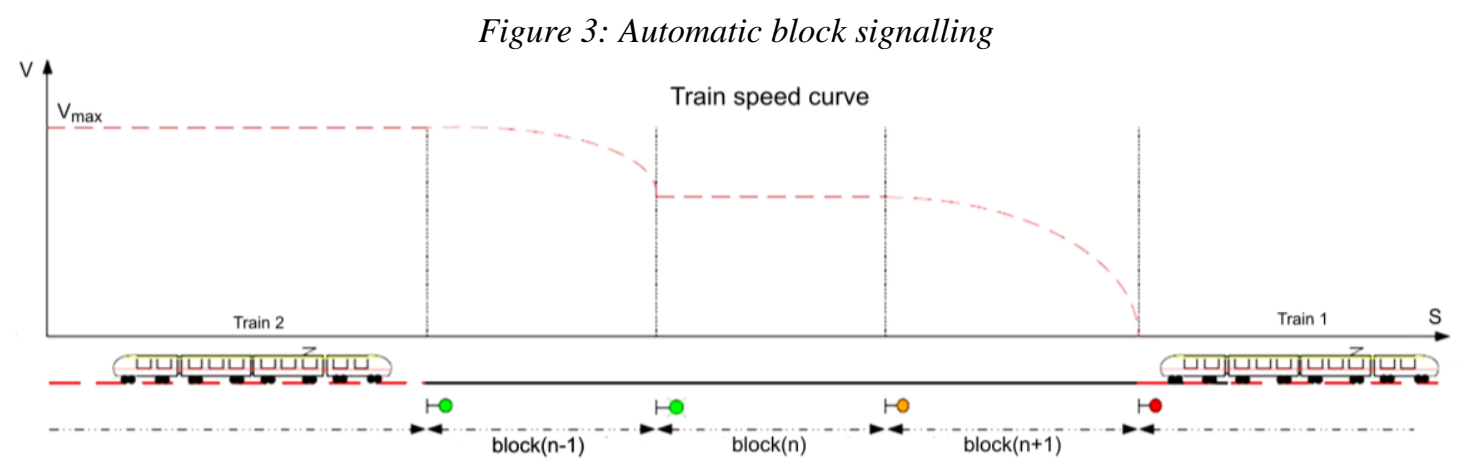

Source: own study

In the simplest systems when the train is detected on the block, the signal automatically displays "stop" until the train enters the second block. Then interlocking system changes the state of both signals, accordingly "clear" for the previous signal and the "stop" for just passed signal. More complicated systems allow to inform train driver about the necessity of braking in advance.

\section{Methodology}

\subsection{Life cycle cost analysis}

The concept of product's life cycle was first published in 1965 by Theodore Levitt. Nevertheless, the analysis of life cycle cost, in a form similar to its present form, began to disseminate in the 1980's. At that time it was used inter alia in the American armaments industry. The first indications of its practical use come from the US Department of Defence's programs, for example "Acquisition Category One (ACAT I)". In the years 1983 - 1984 the US Department of Defence issued a number of LCC analysis guides used by US commercial enterprises until today, for example MIL-HDBK-259 (1983). After this period, the life cycle cost analysis was disseminated to other industries, among others in energy sector, according to 
Lukasik et al. (2016), and Korczak et al. (2016), transportation or oil industry, stated by Kawauchi \& Rausand (1999), and Wolter (1997). Nowadays, LCC is often used as a decisionmaking tool for assessing the cost-effectiveness of alternative solutions whenever they are equally suitable to be implemented on technical grounds. In many countries, it is an element required by law during tender procedures.

The life cycle cost of a technical object is the total cost incurred from the concept and design to the removal from the use. The understanding of the life cycle and actions taken in the subsequent phases of this cycle is essential for the LCC cost estimation concept. The understanding of the life cycle and actions taken in the subsequent phases of this cycle is essential for the LCC cost estimation concept. It is also important to understand the relationship between these between these actions and performance, reliability, maintainability and other technical properties of the object and the resulting costs.

According to EN 60300-3-3 norm, the product's life cycle consists of the six main phases shown in Figure 4.

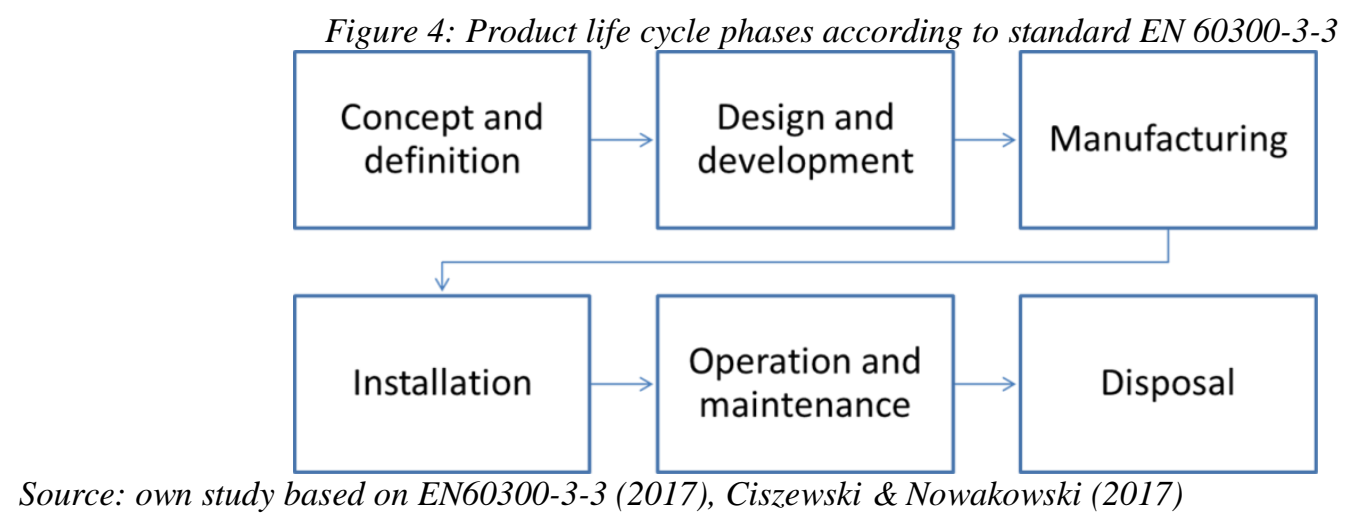

The total costs incurred in the mentioned above phases can be divided into Life Acquisition Costs (LAC), Life Ownership Costs (LOC) and Life Loss Costs (LLC), according to EN603003-3 (2017), and Kawauchi \& Rausand (1999), as is shown Figure 5.

$$
\mathrm{LCC}=\mathrm{LAC}+\mathrm{LOC}+\mathrm{LLC}
$$

Figure 5: Cost categories

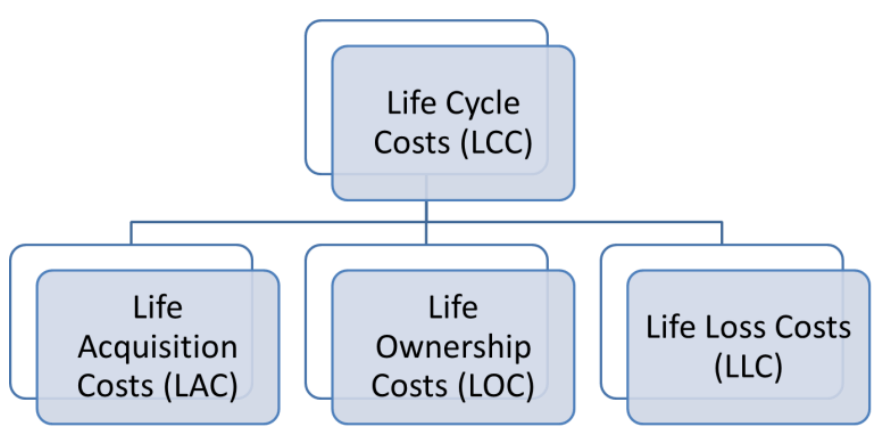

Source: own study

Life acquisition costs or other investment costs are incurred mainly in the first four phases of the life cycle cost. They are, in fact, the only element of LCC' analysis that is easy to calculate prior to the decision of buying or upgrading.

Life ownership costs related to lifetime of the technical system are incurred in the last four phases. It is much harder to perceive them, and even more serious is to estimate them. They are important not only for the buyer but also for the supplier, for example due to the need to provide 
an appropriate warranty period or technical support. The ownership costs are usually the highest component of cost and in many cases far exceed the acquisition costs. The authors know examples of analyses carried out for transport facilities and for means of transport, where the share of LOC in LCC ranged from 60 to over 90\%. It is important to realize this proportion before buying or upgrading, in hence to avoid the negative surprise of high ownership costs in phase of the system operation.

The process of the identify and analyse all of the costs related to product acquiring and ownership is carried out for the assumed period of time or for the whole lifetime.

Life loss costs are connected with withdrawing the system from use and its possible disposal. In case of some facilities they can constitute the considerable part of overall LCC costs. This applies in particular to those facilities whose neutralization is extremely burdensome (for example radioactive materials) or technologically advanced and logistically complex (for example scrapping of ships, rail vehicles, rail infrastructure, etc.), stated by Wessels \& Sillivant (2015). These costs are taken into account in the analysis when the assumed analysis horizon includes the stage withdrawal of an object from operation.

Figure 6: The basic steps in LCC analysis

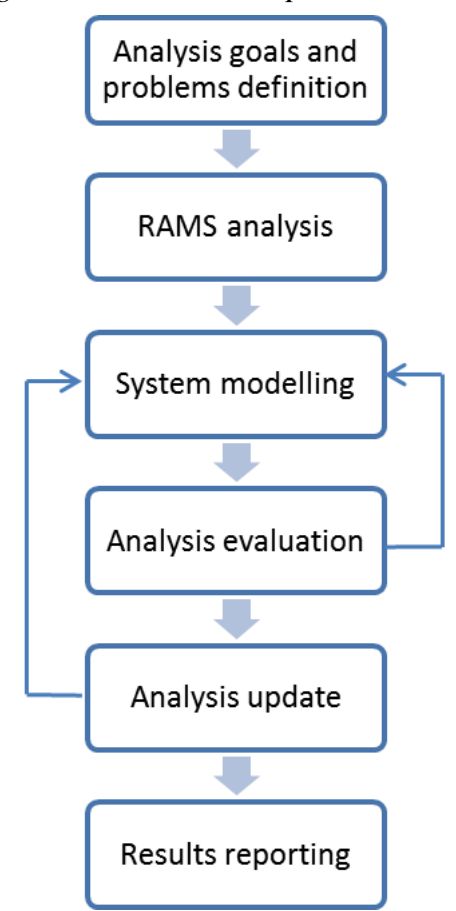

Source: own study based on EN60300-3-3 (2017), Kawauchi \& Rausand (1999), Tulowiecki \& Szkoda (2007), and Ciszewski \& Nowakowski (2017)

Calculation of individual cost components is possible using a variety procedures and estimations, for example: analogous cost estimating, parametric cost estimating, or engineering cost estimating, stated by Dhillon (2010). Among many different procedures for calculating LCC cost, EN 60300-3-3 norm offers a relatively compromise and universal approach, according to EN 60300-3-3 (2017), and Tulowiecki \& Szkoda (2007). The stages of this approach are shown in Figure 6.

The steps of this procedure for three diverse railway traffic control system will be described and discussed below. A level crossing protection system (LCPS), axle counting system (ACS) and automatic block signalling will be included into the analysis. 


\subsection{LCC analysis for railway traffic control systems}

\subsubsection{Analysis goals and problems definition}

The first step in LCC analysis is to identify the problem and determine the estimating aims. Typical analysis goals, expressed in output data categories, are, according to Siciliano et al. (2016), and Tulowiecki \& Szkoda (2007): assessment of the impact of various modernization variants at the LCC cost, identification of cost elements for development work or optimization of modernization variants.

At this stage, the initial definition of characteristics and parameters of the LCC model is recommended. For railway traffic control systems these are, for example, the identification of system structural characteristics, lifetime, traffic estimations, number of staff, etc. It is also necessary to include the requirements of the operation and maintenance manual, such as: interim repairs, expected maintenance time, expected repairs and inspections, as well as traffic safety components, such as personnel training and safety verification.

\subsubsection{RAMS analysis for railway traffic control systems}

RAMS analysis is closely related to the CENELC standards for railway products, and especially to EN 50126. According this norm the producer of the railway traffic control system is obliged to conduct RAMS analysis, in the following evaluation criteria were defined by EN50126 (2002):

1. Reliability - probability that the given product can perform a required functions under given conditions for the given time interval:

- Mean Time Between Failures (MTBF),

- Mean Time To Failure (MTTF).

2. Availability - Ability of the product to be in the state to perform a required functions under given condition at a given instant of time or over given time interval assuming that the required external resources are provided (availability is expressed in the per cent or as the probability).

3. Maintainability - probability of restoring the efficiency for object in the stated time:

- Mean Time To Repair (MTTR),

- Mean Time Between Maintenance (MTBM),

- Mean Time To Maintenance (MTTM),

- maintenance costs,

- operational costs,

- Life-cycle costs (LCC)

4. Safety - freedom from a unacceptable risk of harm.

An EN 50129 standard is devoted to issues of analysis of threats and risk, as the combination of the probability and potential consequences of the determined dangerous event. This norm defines the safety as the lack of the unacceptable risk. The system is being regarded safe, if the risk is associated with the functioning of the system is acceptable. For railway traffic control systems safety integrity is specified as one of four discrete levels SIL (Safety Integrity Level). SIL is specifying safety integrity requirements of the safety functions to be allocated to the safety related systems defined through the Tolerable Hazard Rate (THR), according to Pniewski et al. (2016), and Kornaszewski (2008). The THR value is determined analytically. The least restrictive requirements concern the level SIL1, the most SIL4 (Table 1). 
Table 1: Tolerable Hazard Rates and Safety Integrity Level according to EN 50129

\begin{tabular}{ll}
\cline { 2 - 2 } Tolerable Hazard Rates (THR) & Safety Integrity Level (SIL) \\
\cline { 2 - 2 } $10^{-9} \leq \mathrm{THR}<10^{-8}$ & 4 \\
$10^{-8} \leq \mathrm{THR}<10^{-7}$ & 3 \\
$10^{-7} \leq \mathrm{THR}<10^{-6}$ & 2 \\
$10^{-6} \leq \mathrm{THR}<10^{-5}$ & 1 \\
\hline Source: EN50129 (2007)
\end{tabular}

European standards are imposing an obligation to apply the safety analysis in the process of the decision making about implementation the system for the use. With reference to programmable systems (the modern railway traffic control system are programmable) in the safety analysis methodology defined in the EN 50128 norm is often used. However, in order to achieve the safe communication between elements of railway traffic control system one should consider the recommendations included in the EN 50159 norm.

Figure 7: " $V$ " - model of the rail traffic control system life cycle

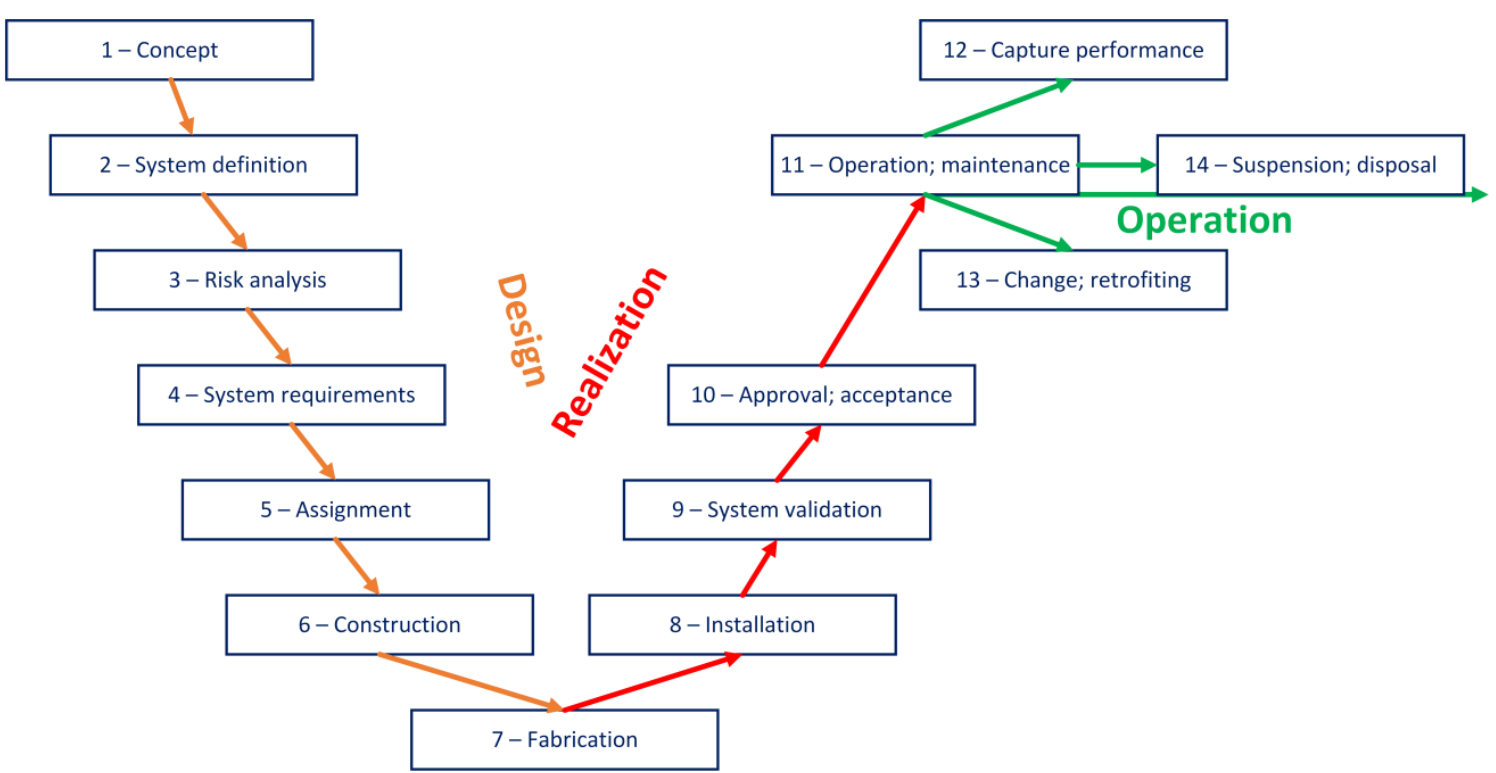

Source: own study based on EN50129 (2007)

According to the EN 50129 norm the risk analysis is carried out in a document called a "safety case". This document is required at the stage of system certification, after the completion of steps 1-6, in accordance with the "V" model of the system life cycle with accordance with EN 50126 norm, as shown Figure 7. Common Safety Method (CSM) in the scope of valuation and risk assessment helps to ensure of the safety level of the Community railways, based on Kornaszewski (2008).

The left side of the "V" model is determined in the norm as system development, whereas the right side is related with its installation, acceptance and operation according to EN50126 (2002), EN50129 (2007), EN50128 (2011).

System reliability evaluation is not only an essential element of ensuring safety, but is also helpful in estimating the costs of its operating. Reliability costs include, for example interim review, maintenance, modernisation or upgrading the skills of staff costs.

In most studies on this issue, systems failure losses are treated as a determined amount which include the cost of downtime and the cost of repairs. In fact, there are also losses that are a direct consequence of a system failures, such as the loss of expected benefits or costs of the necessary changes in traffic organisation. It is even more difficult to estimate the effects of loss 
of company reputation and prestige. The dependencies between reliability and economic effects are therefore not easy to identify, argued by Lukasik et al. (2016), and Bester \& Torun (2014), but even a rough estimation of them gives some possibilities for comparing the efficiency of objects with different reliability, argued by Strauss et al. (2015).

\subsubsection{System modelling}

The LCC model is a simplified representation of reality and defines only that components and properties, which are significant in analysis. The model should be clear and easy to use, update and modify. It should also provide the possibility of a separate analysis of the individual components (EN60300-3-3, 2017). Developing a LCC cost model includes: cost breakdown structure (CBS) designing and product breakdown structure (PBS) designing, as well as identifying and estimating costs elements and parameters, stated by Caetano \& Teixeira (2015), and Caetano \& Teixeira (2016).

Figure 8: Total cost calculation 3D matrix

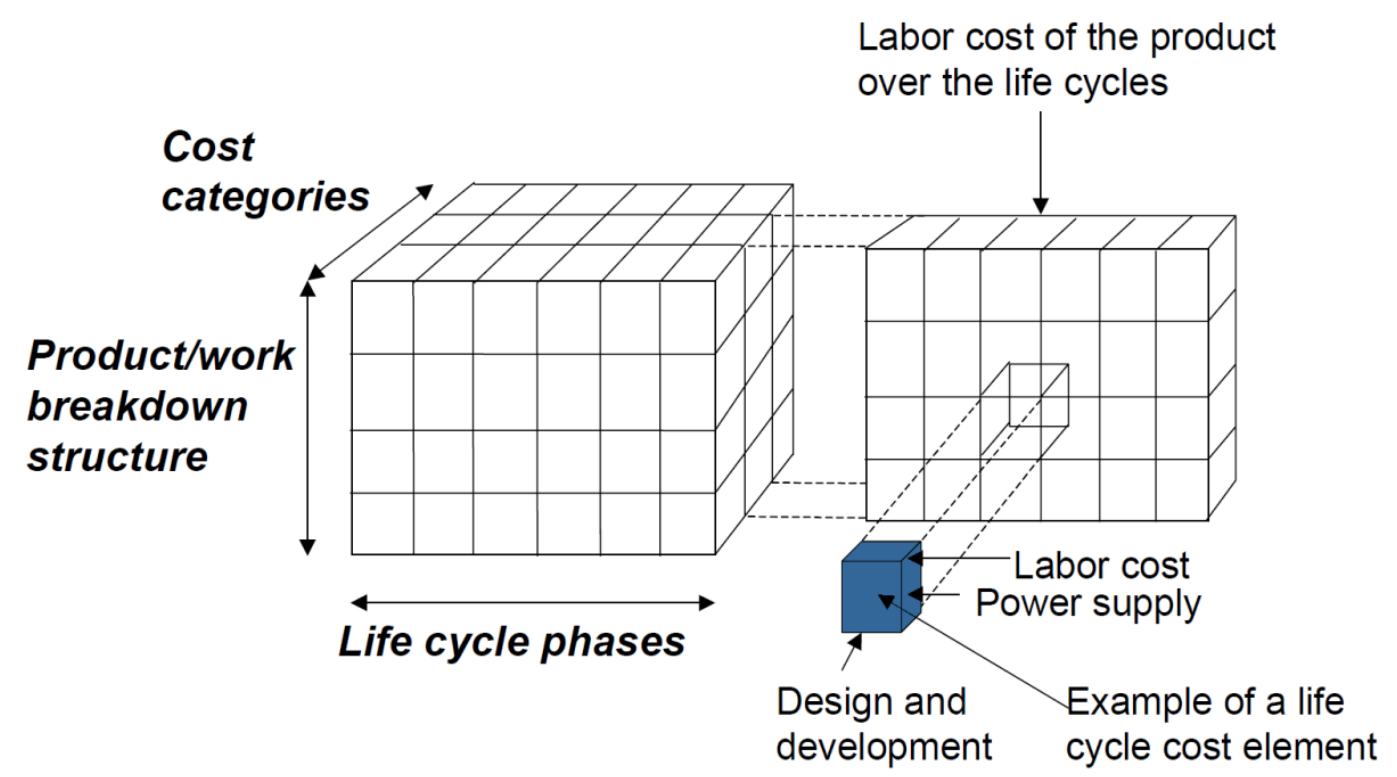

Source: own study based on Kawauchi \& Rausand (1999), EN60300-3-3 (2017)

The definition of the costs included in the model and determination the method of its estimation is the basis for the construction of the correct LCC model. The selection of the methods depends on the specific object of research.

CBS is decomposing top-level costs into component costs. In accordance with the international EN 60300-3-3 standard, each category should be divided until achieving the lowest level containing cost elements. The value of the element is expressed by the function, its parameters and/or constant values, according to the type of cost. One of the ways of the cost calculation is the use of three-dimensional matrix, according to EN60300-3-3 (2017), and Kawauchi \& Rausand (1999), which dimensions are: product breakdown structure, life cycle phases and cost categories (Figure 8).

Such type of approach is systematized and well-organized, and thus provides a high level of trustfulness that all elements significant in the total LCC cost have been taken into account. Specialized tools can also be used to perform LCC costing, according to Castlo et al. (2014). 


\subsubsection{Analysis evaluation}

In order to confirm the accuracy and consistency of the results, the analysis review is made by EN60300-3-3 (2017). It includes: validation of objectives and scope of the analysis, verification of the analysis assumptions and their documentation, verification of the model, input data checking as well as results consistency and their interpretation. If deficiencies are found, it is necessary to modify and improve the original concept.

\subsubsection{Analysis update}

Estimation the LCPS life cycle costs require a broad spectrum of acquired data. Especially for new systems, historical data, such as reliability or maintainability, which for the purposes of analysis needs to be estimated and expressed in terms of costs, are not initially available. In such cases, it is recommended to update the analysis using real data when it becomes available, argued by Kawauchi \& Rausand (1999), and Obrenovic et al. (2004).

\subsubsection{Results reporting}

According to international standard EN 60300-3-3, documentation of LCC analysis is mandatory. It is recommended to report clearly the results of the analysis as well as their implications. The standard specifies the elements of the LCC calculation report.

Figure 9: Railway traffic control system cost categories defined for LCC analyse
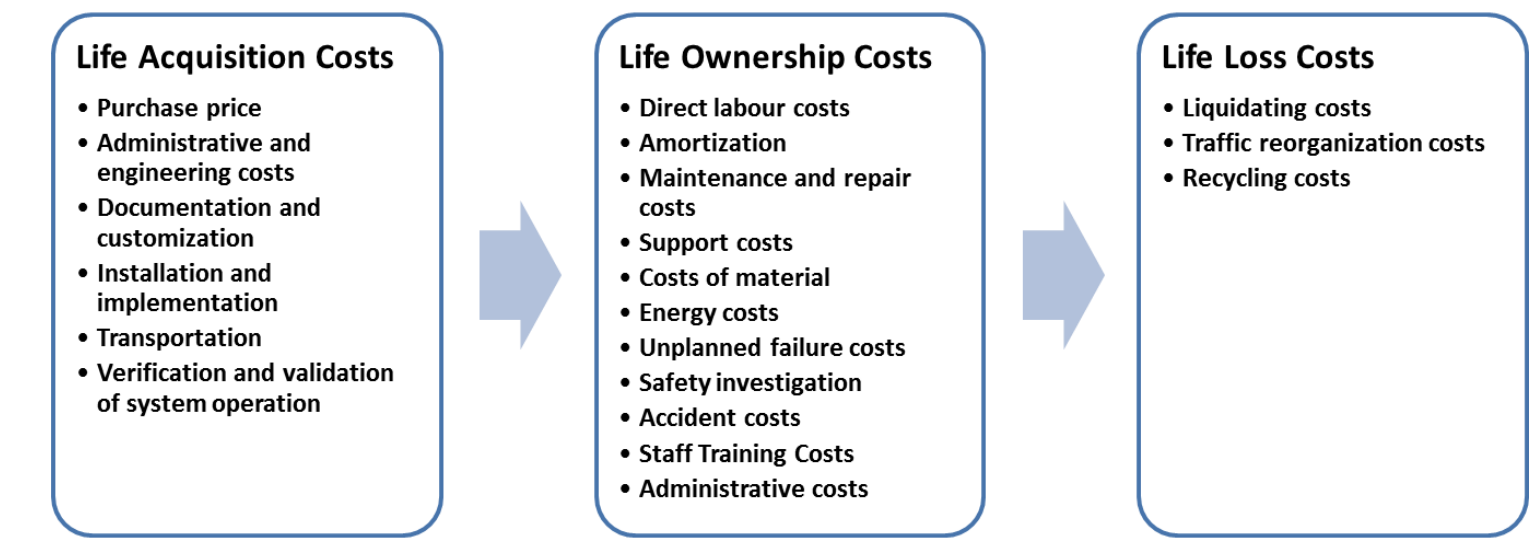

Source: own study

\section{Results and Discussion}

The authors used a simplified LCC analysis method to estimate life-cycle costs for selected railway traffic control systems. The analysis was carried out for a level crossing protection system (LCPS), axle counting system (ACS) and automatic block signalling. Different cost categories exist in particular systems, however, the authors used identical cost categories for all analysed systems in the shown examples to allow comparison of cost structures. At the same time, if the cost category does not exist in the given system, its value was set to 0 .

The cost categories included in the systems analysis and their location in the system life-cycle are shown in Figure 9.

For the purposes of the analysis, the minimum for railway traffic control systems lifetime $\mathrm{T}=15$ years was assumed. The cost structure of the LCPS system is shown in Figure 10. 
Figure 10: Life cycle costs structure for LCPS system

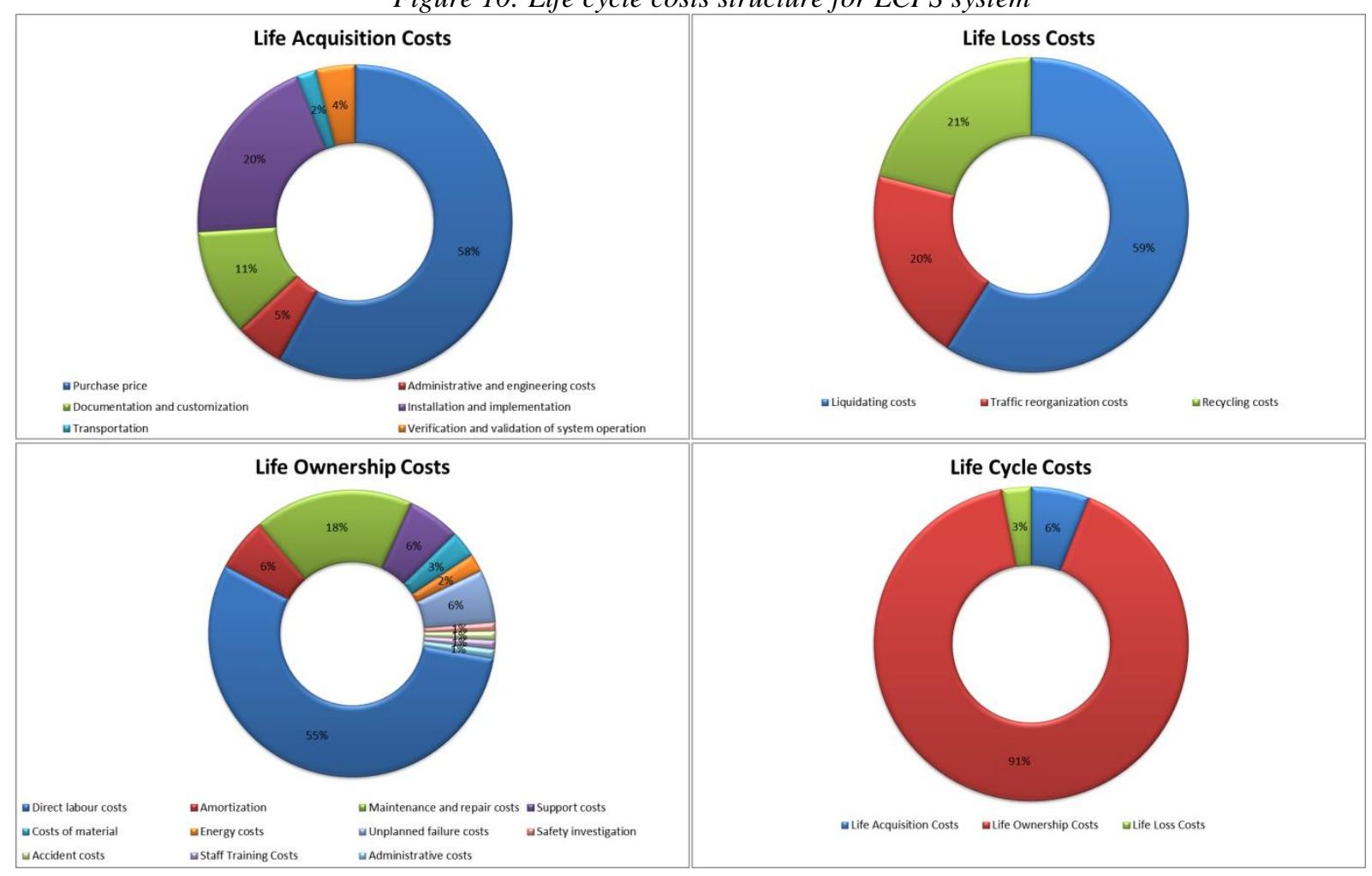

Source: own study based on authors' calculations

The high share of ownership costs in the total life-cycle costs and a large share of direct labor costs in the cost of ownership is clearly visible on Figure10. It is typical for non-fully automated systems.

The cost structure of the axle counting system is shown in Figure 11. Because the system is fully automatic direct labour costs are in this case 0 , and costs of ownership have much smaller share in the total costs.

In the case of the most expensive system, an automatic block signalling, for which the cost structure is shown in Figure 12, the system is almost fully automated. However, there are direct labour costs related to the operation of home and exit signals.

The analysed systems vary significantly at the cost of purchase and the degree of automation. It has a great impact on the total life-cycle cost structure. Nevertheless, for all systems under consideration, the ownership cost is significant and varies between $35 \%$ and $91 \%$. Another important and common components of total costs are elements related to ensuring safety. 
Figure 11: Life cycle costs structure for axle counting system

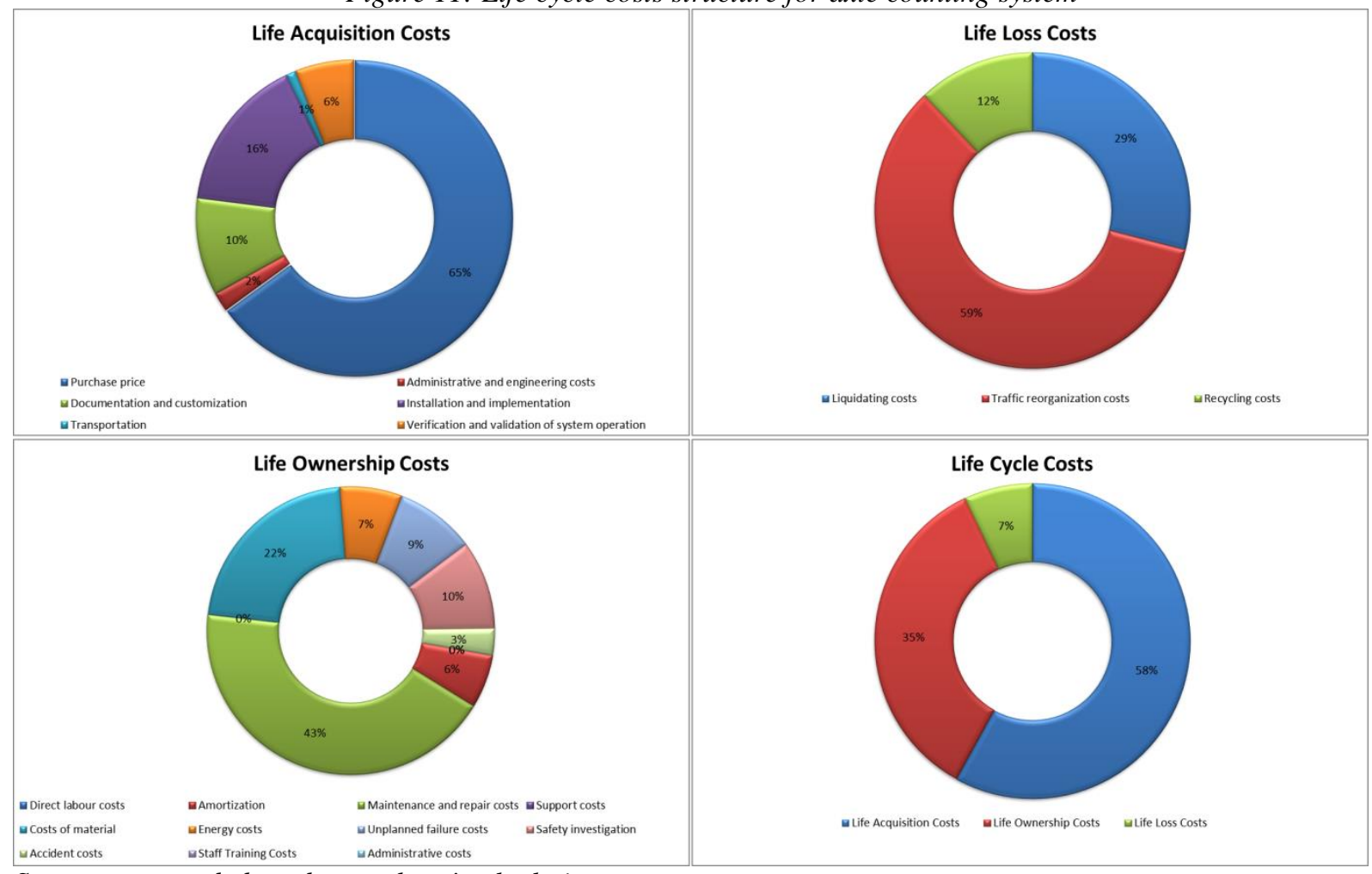

Source: own study based on authors' calculations

Figure 12: Life cycle costs structure for automatic block signalling

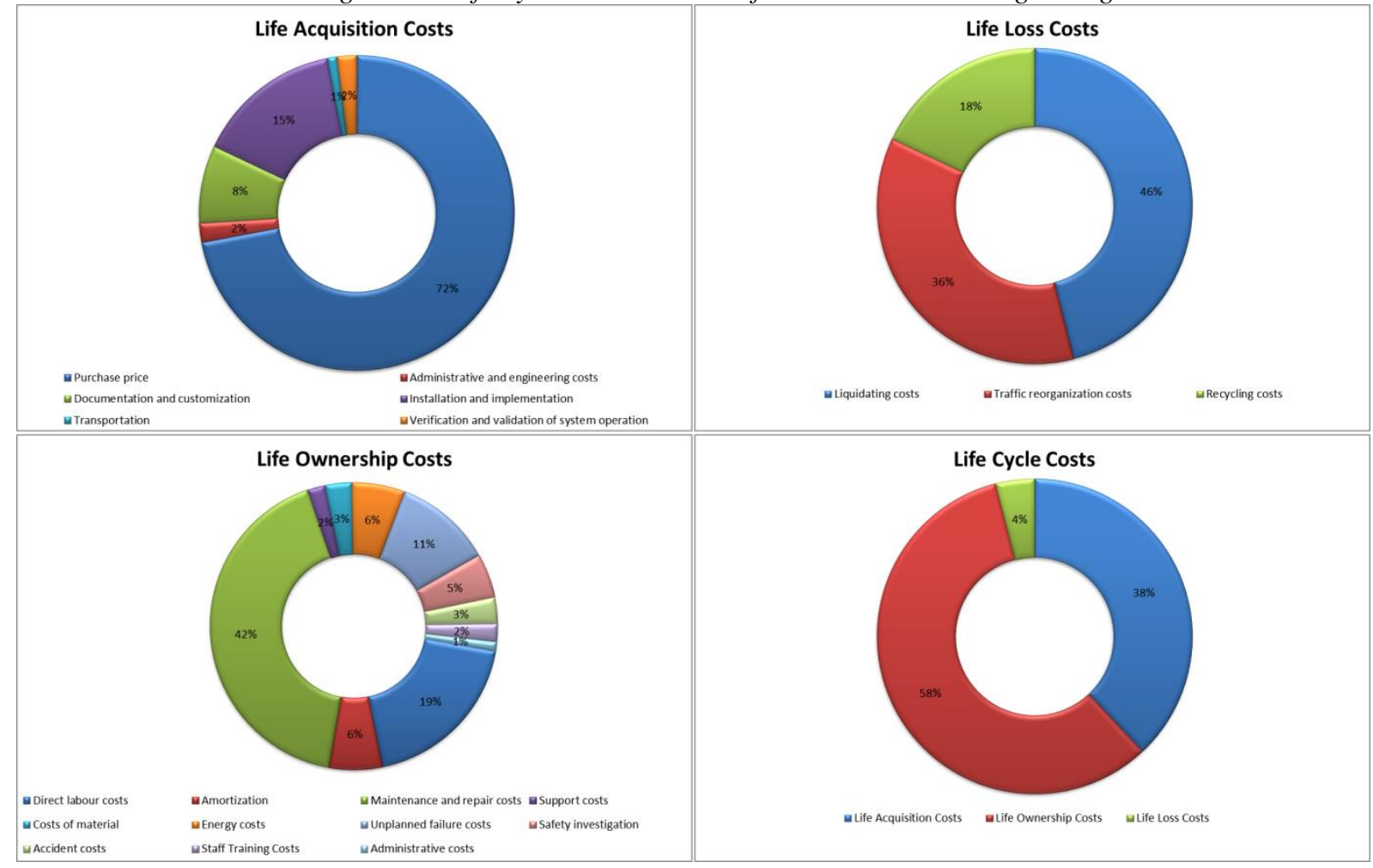

Source: own study based on authors' calculations 


\section{Conclusion}

Not only the initial cost but also the expected costs of the operation and maintenance throughout the whole product life cycle have an impact for investment decisions regarding the construction or modernization of railway traffic control systems. Initial investment decisions affect the later stages of the facility's operation. LCC analysis can be successfully applied to assess the effectiveness of individual upgrades or individual systems. It provides clear and probable, expressed in costs information on the consequences of the adopted concepts. Reliable information on the design and maintenance cycle leads to improved quality and availability of built systems, while increasing transparency in decision making. The effectiveness of the method depends not only on the assumptions and model correctness, but also on the availability of technical expertise and the data necessary to estimate the component costs. In contrast to economic methods of effectiveness evaluation, LCC analysis takes into account the reliability features of the rail traffic control systems.

\section{Acknowledgment}

This material is based upon work supported by National Centre for Research and Development under Grant No. PBS3/A6/29/2015 entitled "The system for maintenance data acquisition and analysis of reliability and safety of traffic control systems".

\section{References}

Bester, L. \& Torun, A. (2014). Modeling of Reliability and Safety at Level Crossing Including in Polish Railway Conditions. Telematics - support for transport Book Series: Communications in Computer and Information Science, 471, 38-47.

Burdzik, R., Nowak, B., Młynczak, J. \& Deuszkiewicz, P. (2016). Analysis Of The Detection And Crossing Signaling System In Safety Terms, Diagnostyka, 17(4), 65-72.

Caetano, L.F. \& Teixeira, P. F. (2015). Optimisation Model to Schedule Railway Track Renewal Operations: A Life-Cycle Cost Approach. Structure and Infrastructure Engineering, 11(11), 1524-1536.

Caetano, L.F. \& Teixeira, P.F. (2016). Strategic Model to Optimize Railway-Track Renewal Operations at a Network Level. Journal of Infrastructure Systems, 22(2).

Calixto, E. (2013). Integrated RAMS Analysis Methodology: The Railway Case Study. Proceedings of the 22nd Annual Conference on European Safety and Reliability (ESREL), Safety, Reliability and Risk Analysis: Beyond the Horizont. Amsterdam, Netherland: 1281-1290.

Castlo, D., Linneberg, P. and Puddicombe, R. (2014). Life-cycle assessment tool for railway infrastructure. 7th International Conference on Bridge Maintenance, Safety and Management (IABMAS). Shanghai, China: 10641068.

Ciszewski, T. \& Nowakowski, W. (2017). Life-cycle Cost Analysis for Rail Control Systems. Proceedings of the 17th International Scientific Conference Globalization and Its Socio-Economic Consequences. Rajecke Teplice, Slovakia.

Dhillon, B.S. (2010). Life-Cycle Costing for Engineers.

EN50126. (2002). Railway Applications - The Specification and Demonstration of Reliability, Availability, Maintainability and Safety (RAMS).

EN50128. (2011). Railway Applications - Communication, Signalling and Processing Systems. Software for Railway Control and Protection Systems.

EN50129. (2007). Railway Applications - Communication, Signalling And Processing Systems. Safety Related Electronic Systems For Signalling.

EN60300-3-3. (2017). Dependability Management. Application Guide. Life Cycle Costing.

Kawauchi, Y. \& Rausand, M. (1999). Life Cycle Cost (LCC) Analysis in Oil and Chemical Process Industries.

Korczak, A., Olczykowski, Z. \& Wojciechowski, J. (2016). The Smart Grid Technology in Poland As a Part of Global Electric Power System. Proceedings of the 16th International Scientific Conference Globalization and Its Socio-Economic Consequences, Part II. Rajecke Teplice, Slovakia: 945-952. 
Kornaszewski, M. (2008). Safe Computer Solutions Applied in New Generation Railway Traffic Control Systems. Computer Systems Aided Science And Engineering Work in Transport, Mechanics and Electrical Engineering. Radom.

Kornaszewski, M., Chrzan, M. \& Olczykowski, Z. (2017). Implementation Of New Solutions of Intelligent Transport Systems in Railway Transport in Poland. Smart Solutions in Today's Transport. Communications in Computer and Information Science, (715), 282-292.

Lewinski, A. \& Perzynski, T. (2010). The Reliability and Safety of Railway Control Systems Based on New Information Technologies. Communications in Computer and Information Science, (104), 427-433.

Łukasik, Z., Ciszewski, T., Młyńczak, J., Nowakowski, W. \& Wojciechowski, J. (2016). Assessment of the Safety of Microprocessor-Based Semi-automatic Block Signalling System. Contemporary challenges of transport systems and traffic engineering. Book Series: Lecture Notes in Networks and Systems, 137-144.

Łukasik, L., Ciszewski, T. \& Wojciechowski, J. (2016). Power Supply Safety of Railway Traffic Control Systems As a Part of International Transport Safety. Proceedings of the 16th International Scientific Conference Globalization and Its Socio-Economic Consequences, Part III. Rajecke Teplice, Slovakia: 1212-1219.

Mikulski, J. \& Młyńczak, J. (2011). Railroad Level Crossing - Technical and Safety Trouble, Transport Systems and Processes. Marine Navigation and Safety of Sea Transportation, 69-76.

MIL-HDBK-259. (1983). Military Handbook. Life Cycle Cost in Navy Acquisitions. Global Engineering Documents.

Nowakowski, W., Ciszewski, T. \& Łukasik, Z. (2017). The Concept of Railway Traffic Control Systems Remote Diagnostic. Communications in Computer and Information Science, (715), 471-481.

Nowakowski, W., Łukasik, Z. \& Bojarczak, P. (2016). Technical Safety in The Process of Globalization. Proceedings of the 16th International Scientific Conference Globalization and Its Socio-Economic Consequences, Part IV. Rajecke Teplice, Slovakia: 1571-1578.

Obrenovic, M., Jaeger, B. \& Lemmer, K. (2006). Methodology for the LCC-Analysis and the Optimal Migration of The Railway Operations Control on The Example of ETCS. Computers In Railways X: Computer System Design and Operation in The Railway and Other Transit Systems, (88), 255 - 264.

Pniewski, R., Kornaszewski, M. \& Chrzan, M. (2016). Safety of Electronic ATC Systems in The Aspect of Technical and Operational. Proceedings of the 16th International Scientific Conference Globalization and Its Socio-Economic Consequences, Part IV. Rajecke Teplice, Slovakia: 1729-1735.

Puz, U. \& Bogensperger, S. (2013). LCC Monitoring for Railway Infrastructure. Beton-und Stahlbetonbau (Special Issue), 150-153.

Siciliano, G. et al. (2016). Adapted Cost-Benefit Analysis Methodology for Innovative Railway Services. European Transport Research Review, 8(4).

Strauss, A. et al. (2015). Comprehensive Infrastructure Life-Cycle Assessment. Fourth international symposium on life-cycle civil engineering. Tokyo, Japan: 200-207.

Tułowiecki, A. \& Szkoda, M. (2007). Koszt Cyklu Trwałości LCC Jako Model Decyzyjny Modernizacji Pojazdów Szynowych. Zeszyty Naukowe Instytutu Pojazdów, 1(64).

Wessels, W.R., \& Sillivant, D. S. (2015). Affordable reliability engineering. Life-Cycle Cost Analysis for Sustainability and Logistical Support.

Wolter, W. (1997). Practical RAMS- and LCC-Requirements - But How Are The Railways Dealing With This? System Optimization For Railway Traffic: Life-Cycle Costs, Reliability, Maintenance And Availability Of Railway Vehicles, (1344), 25-43. 